\title{
THE FEDERAL RESERVE BANK
} of ST. LOUIS

\section{Inflation Targeting in a Small Open Economy: Empirical Results for Switzerland}

\author{
Michael Dueker \\ Andreas M. Fischer
}

Working Paper 1995-014A

http://research.stlouisfed.org/wp/1995/95-014.pdf

PUBLISHED: Journal of Monetary Economics, February 1996.

\section{FEDERAL RESERVE BANK OF ST. LOUIS}

Research Division

411 Locust Street

St. Louis, MO 63102

The views expressed are those of the individual authors and do not necessarily reflect official positions of the Federal Reserve Bank of St. Louis, the Federal Reserve System, or the Board of Governors.

Federal Reserve Bank of St. Louis Working Papers are preliminary materials circulated to stimulate discussion and critical comment. References in publications to Federal Reserve Bank of St. Louis Working Papers (other than an acknowledgment that the writer has had access to unpublished material) should be cleared with the author or authors.

Photo courtesy of The Gateway Arch, St. Louis, MO. www.gatewayarch.com 


\title{
INFLATION TARGETING IN A SMALL OPEN ECONOMY: EMPIRICAL RESULTS FOR SWITZERLAND
}

\begin{abstract}
This paper extends McCallum's (1987) nominal targeting rule to a small open economy by allowing for feedback from the exchange rate. Instead of setting parameters in a McCallum-type targeting rule and simulating, the parameters are estimated using a markov switching model. We argue that a model of discrete parameter changes should be adept at capturing sudden changes in policy regime, such as changes in the degree to which monetary policy admits feedback from the exchange rate. We examine the legitimacy of an inflation targeting rule with occasional exchangerate feedback to describe Swiss monetary policy over the past twenty years.
\end{abstract}

KEYWORDS:. Inflation Targeting, Exchange Rate Feedback, Markov Switching

JEL CLASSIFICATION: C50, E52, E58

Michael Dueker

Economist

Federal Reserve Bank of St. Louis

411 Locust Street

St. Louis, MO 63102
Andreas M. Fischer

Swiss National Bank

Postfach 8022

Zurich, SWITZERLAND

(41 1) 6313901

Fax (41 1) 6313294 


\section{Inflation Targeting in a Small Open Economy: Empirical Results for Switzerland}

\section{Introduction}

The primary purpose of nominal feedback rules for monetary policy of the type suggested by McCallum $(1987,1988)$ is to prescribe a time path for an instrument variable which would engender relatively smooth non-inflationary growth in nominal spending. Because it appears unlikely, however, that a central bank would renounce discretion altogether and adhere strictly to a rule, feedback rules have two likely empirical uses. The first is to provide policymakers a reference to guide them in their instrument settings. Policymakers could consult a nominal feedback rule, which is in line with their long-run inflation goal, while retaining the flexibility to lessen short-term volatility in credit markets. The second empirical use is to model past policy under the maintained hypothesis that monetary policy has been implicitly following a feedback rule. By describing past policy with a feedback rule, one can ascertain the implicit goals of past policy and when those goals appeared to change. This article attempts to illustrate both empirical functions, using in-sample results to describe Swiss monetary policy from 1974 to 1987 and out-of-sample results to suggest how modeling monetary policy with a nominal feedback rule might provide useful and timely information to policymakers.

Variants of McCallum's GNP rule have been applied to the U.S. economy as well as various small open economies. ${ }^{1}$ The empirical exercises concentrate primarily on counter-

\footnotetext{
${ }^{1}$ See McCallum $(1993,1994)$ for Japan and Hall (1990) for Germany, Japan, and Canada.
} 
factual simulations and lend support to the claim that a nominal GNP rule could stabilize nominal fluctuations. If one, however, attempts to describe actual monetary policy in a small open economy, the exchange rate ought to be explicitly taken into account. There is ample evidence that exchange rate concerns lead to disruptions in the path of money growth in small open economies. In addition, the degree to which monetary policy accepts feedback from the exchange rate changes continuously. Therefore, a constant parameter model is unlikely to explain monetary policy choices in open economies.

The strategy of this paper is to develop an inflation targeting rule with markov-switching feedback coefficients on both the exchange rate and the price level. A model of discrete parameter changes should be adept at capturing sudden changes in policy regime, i.e., whether or not monetary policy responds strongly to exchange-rate developments. Instead of setting parameters and simulating as in McCallum (1987), the time-varying parameters are estimated in our framework. Hence, by using a variant of McCallum's rule to estimate a model of actual policy choices, we employ it in a positive exercise to complement the normative simulations undertaken in McCallum's work.

The objectives for analyzing an inflation targeting rule for Switzerland are two-fold. The first is to examine whether the Swiss practice of monetary targeting is consistent with an inflation targeting rule. Although the Swiss National Bank (SNB) has never announced a formal inflation target, price stability is widely recognized as the overriding goal of Swiss monetary policy. It is of interest to determine whether Swiss monetary policy has maintained its implicit long-run inflation target even during periods of exchange rate 
targeting and periods of above-normal inflation. The identification of a low implicit inflation target represents a direct test of SNB claims that price stability is the primary objective of Swiss monetary policy. The second objective is to carry the estimated model forward to the 1988-94 period and examine its out-of-sample properties. The latter period followed a major reduction in reserve requirements and the introduction of a new payments system, and thus provides a test of McCallum's criterion that a nominal targeting rule ought to be impervious to financial innovations and regulatory changes.

The paper is organized as follows. Section 2 presents an informal account of Swiss monetary policy since the end of the Bretton Woods system. A brief characterization of this period is necessary in order to determine whether the empirical model generates results consistent with known regime shifts. Section 3 presents the inflation targeting model with markov switching. The model depicts an implicit inflation targeting rule which allows for time-varying feedback from an exchange rate target. The estimation results for the 19741987 period are presented in section 4 . The same section also discusses the out-of-sample performance of the model. Section 5 offers several conclusions.

\section{General Features of Swiss Monetary Policy}

"The Swiss National Bank has been setting monetary targets for well-nigh fifteen years. On several occasions however, notably in 1978, it has had to deviate from its course for exchange rate reasons. If the principle of monetary targeting had been legally enforced, would we have violated the law or would we have allowed the Swiss franc to appreciate beyond all reasonable limits? ... A central bank must thus be constantly on the alert and implement its monetary target with the required flexibility."

Markus Lusser, President of the Board of Governors, Swiss National Bank [Lusser 
The SNB has regularly announced monetary targets since the breakdown of the Bretton Woods System. ${ }^{2}$ Rich (1995) reviews the SNB's targetry framework and notes three policy principles. First, price stability is recognized as the main and ultimate goal of monetary policy. Second, the SNB's position is that achievement of price stability is to be based on the control of the money stock. Third, the targetry framework acts as a precommitment device.

The SNB's strategy of announcing monetary targets should not be interpreted as a strict policy rule. Rather, the SNB's approach to monetary targeting may best be described as a contingent rule. The targets are designed to impose a medium to long-term constraint on money growth with allowance for short-run flexibility to react to unanticipated shocks. For instance, the SNB has made clear in its policy statements that it reserves the right to intervene in the foreign exchange market when it feels that an excessive appreciation of the Swiss franc could harm the real economy.

As in other countries, money growth targets are based on explicit inflation goals and forecasts of potential output and velocity growth. Starting in 1975, the targets were first set for the annual growth of the monetary aggregate M1, where M1 was steered by a multiplier model using the monetary base as the instrument. After a brief interlude of exchangerate targeting, annual monetary targets were set for the monetary base beginning in 1980 .

\footnotetext{
${ }^{2}$ See Rich (1995) for a detailed account of Swiss monetary policy and Bernanke and Mishkin (1992) for an international comparison.
} 
Finally, in 1990 annual targets were replaced by a five-year target path. The evolution of the target framework reflects changes in style rather than substance, because the basic approach - using the monetary base as the instrument to aim for price stability - has remained the same.

Although price stability was emphasized as the main goal of Swiss monetary policy, annual inflation averaged 3.76 percent for the period 1973-1994. In particular there were three notable inflation cycles. Figure 1 shows that inflation peaked in 1974, 1981 and 1991. The same graph shows that inflation was preceded by an acceleration and subsequent deceleration of monetary base growth in both 1974 and 1981. The most recent inflation cycle is marked, in contrast, by a sudden fall in base growth beginning in 1988. Despite the contraction in base growth, the 1988 shock should not be considered a period of monetary tightening. As discussed below, technological and institutional factors significantly reduced the demand for reserves.

The first episode of high growth in the monetary base reflects the liquidity overhang from the final years of the Bretton Woods System when the SNB had to buy foreign exchange to keep the exchange rate stable. With ine advent of base control, this overhang was reduced and as consequence the Swiss franc appreciated. In response to the strengthening exchange rate, the SNB let the monetary base expand in 1974. After a further sharp appreciation of the Swiss franc in 1978 (see figure 1), monetary targeting was temporarily abandoned in favor of a policy of exchange rate targeting. Swiss monetary authorities feared that the appreciation of the Swiss franc would erode the competitive position of Swiss industry. To 
avert a potential slowdown in domestic activity, the SNB announced that it would keep the exchange rate of the Deutsche mark above 0.80 Swiss francs. No monetary target was announced for 1979. The foreign exchange rate interventions necessary to defend this target resulted in an increase in the annual growth of the monetary base of over 25 percent. The massive swings in the base growth during the 1978-1979 period, depicted in Figure 1, capture the period of exchange rate targeting.

After returning to money supply targets in 1980 , the SNB generally hit its base growth targets through 1987. Actual base growth was below target in 1980 and 1981 when the Swiss franc was weak. Then in 1982 and 1983, when the Swiss franc started to appreciate again, endangering a still rather fragile economic recovery, actual base growth exceeded the targets by small margins. A similar situation arose in 1987. In 1988 the demand for base money underwent a permanent downward shift due to two factors: the introduction of the Swiss Interbank Clearing (SIC) system and changes in reserve requirements. ${ }^{3}$ The SIC accelerated the execution of payments and regulatory reforms brought both a reduction in reserve requirements and a switch from contemporaneous to lagged reserve accounting. As a result, the monetary base proved not to be a good indicator for monetary policy during the transition period and the SNB had to look to other indicators such as broader monetary aggregates, interest rates and the exchange rate.

At the risk of generalizing, the narrative approach identifies several periods when exchange rate considerations played a major role. The most significant is the 1978-1979

\footnotetext{
${ }^{3}$ See Vital and Mengle (1988) for a discussion regarding the SIC system.
} 
period, when the monetary target was suspended and replaced by an explicit exchange rate target. Less pronounced episodes include 1975 when the SNB resumed foreign exchange interventions and the years between 1980 and 1983 when the SNB deviated slightly from the monetary target in order to influence the exchange rate.

\section{Description of the Empirical Model}

Our indicator model with markov switching takes the monthly growth rate in the seasonally adjusted monetary base less a forecasted growth rate for real base balances and calls this "intended" inflation for the month. Assuming that the monetary base is the instrument and that our forecasts mirror the general consensus at the time, our "intended" inflation variable should reflect the policy intentions of the central bank across time. In the model fluctuations in intended inflation come from three distinct sources: first, variation in the central bank's long-run inflation target; second, deviations from the price level target; and, third, deviations from the exchange rate target.

The main equation of the feedback model is

$$
\begin{aligned}
\text { Money growth: } \Delta \ln M B_{t}= & \lambda_{0}\left(S 1_{t}\right)+\Delta \ln \left(\frac{M B}{P}\right)_{t \mid t-1}+\lambda_{1}\left(S 1_{t}\right)[\ln \tilde{P}-\ln P]_{t-1} \\
& +\lambda_{2}\left(S 2_{t}\right)[\ln \tilde{e}-\ln e]_{t-1}+\varepsilon\left(S 1_{t}, S 2_{t}\right) \\
& \varepsilon\left(S 1_{t}, S 2_{t}\right) \sim \text { student- } t \\
& \operatorname{var}\left[\varepsilon\left(S 1_{t}, S 2_{t}\right)\right]=\sigma^{2}\left(S 3_{t}\right) \frac{n}{n-2}
\end{aligned}
$$

where $M B$ stands for the seasonally adjusted monetary base, $P$ for the price level, and $\widetilde{P}$ 
for the expected target level not conditional on the values of the state variables. Similarly, $e$ is the exchange rate and $\tilde{e}$ is the expected target rate not conditional on the values of the state variables. The error term $\varepsilon$ is assumed to have a student- $t$ distribution with $n$ degrees of freedom. The forecast for real monetary base demand used to derive the intended inflation rate is denoted by $(M B / P)_{t \mid t-1}$. The Appendix discusses the derivation of the forecasts for the real base growth. Three binary state variables $S 1, S 2$, and $S 3$ are subject to markov switching: ${ }^{4} S 1$ governs switching in parameters related to inflation and/or price level targeting; $S 2$ for parameters related to exchange-rate targeting; and $S 3$ for heteroskedasticity. ${ }^{5}$ The notation $\alpha\left(S_{i}\right)$ indicates that parameter $\alpha$ is subject to markov switching governed by state variable $S_{i}$.

The parameter $\lambda_{0}$ represents the long-run target rate of inflation, because intended inflation will equal $\lambda_{0}$ when price-level and exchange-rate gaps equal zero in the long run. Inferences of the state variable, $S 1$, provide a probability-weighted estimate of the current long-run inflation target: Prob. $\left(S 1_{t}=0 \mid Y_{t}\right) \times \lambda_{0}(S 1=0)+\operatorname{Prob} .\left(S 1_{t}=1 \mid Y_{t}\right) \times \lambda_{0}(S 1=$ 1), where $Y_{t}$ represents information available through time $t$. The sizes of the feedback coefficients, $\lambda_{1}\left(S 1_{t}\right)$ and $\lambda_{2}\left(S 2_{t}\right)$, determine the rate at which price- ${ }^{-1}$ evel and exchange-rate gaps are gradually closed through policy actions.

The price level target and the exchange rate target are defined in equations (2) through (5) to be a weighted average of last period's actual and target levels. In the case of the

\footnotetext{
${ }^{4}$ The basic filtering and smoothing algorithms for a markov-switching model are discussed in Hamilton (1989).

${ }^{5} \mathrm{Kim}(1993)$ notes that markov switching in the variance is an adept alternative to GARCH models for modeling conditional heteroskedasticity or "ARCH" effects.
} 
price target, we also allow for trend growth, $\lambda_{0}$.

$$
\begin{aligned}
\text { Target Price Level: } \ln \widehat{P}_{t}\left(S 1_{t}\right) & =\lambda_{0}\left(S 1_{t}\right)+\delta_{1}\left(S 1_{t}\right) \ln \widetilde{P}_{t-1}+\left(1-\delta_{1}\left(S 1_{t}\right)\right) \ln P_{t-1} \\
\text { Expected target: } \ln \widetilde{P}_{t} & =\sum_{i=0}^{1} \operatorname{Prob}\left(S 1_{t}=i \mid Y_{t}\right) \ln \widehat{P}_{t}\left(S 1_{t}=i\right) \\
\text { Target Exch. Rate: } \ln \hat{e}\left(S 2_{t}\right) & =\delta_{2}\left(S 2_{t}\right) \ln \tilde{e}_{t-1}+\left(1-\delta_{2}\left(S 2_{t}\right)\right) \ln e_{t-1} \\
\text { Expected target: } \ln \tilde{e}_{t} & =\sum_{j=0}^{1} \operatorname{Prob}\left(S 2_{t}=j \mid Y_{t}\right) \ln \hat{e}_{t}\left(S 2_{t}=j\right)
\end{aligned}
$$

The variables $\widehat{P}$ and $\widehat{e}$ are, respectively, the target price level and the target exchange rate conditional on particular values of the markov state variables. Rebasing of the target level occurs for values of $\delta_{1}, \delta_{2}<1$. Consequently, one-time shifts in the price level are gradually accommodated into the target path. As $\delta$ decreases from one, the degree to which the target level is allowed to drift to accommodate recent developments increases. McCallum (1993) has used an analogous weighting scheme; however, in his model $\delta_{1}$ remains constant.

Because of the autoregressive nature of equations (2) and (4), inferences of the state at time $t$ would depend on the entire history of past realizations of the state variables if it were not for the collapsing procedure shown in equations (3) and (5). Kim (1994) provides the justification for the collapsing procedure and notes that its use introduces a small approximation to the evaluation of the likelihood function in a markov-switching model. He finds, however, that the approximation does not materially affect the calculated value of the likelihood function or the parameter estimates. 
We define six transition probabilities for the three state variables:

$$
\begin{aligned}
& \mathrm{P}\left(S 1_{t}=0 \mid S 1_{t-1}=0\right)=p_{1}, \\
& \mathrm{P}\left(S 1_{t}=1 \mid S 1_{t-1}=1\right)=q_{1}, \\
& \mathrm{P}\left(S 2_{t}=0 \mid S 2_{t-1}=0\right)=p_{2}, \\
& \mathrm{P}\left(S 2_{t}=1 \mid S 2_{t-1}=1\right)=q_{2}, \\
& \mathrm{P}\left(S 3_{t}=0 \mid S 3_{t-1}=0\right)=p_{3}, \\
& \mathrm{P}\left(S 3_{t}=1 \mid S 3_{t-1}=1\right)=q_{3} .
\end{aligned}
$$

Implicit in equation (6) is an independence assumption that reduces the number of estimated transition probabilities. In the general case with $k$ state variables, each taking on two values, one would need to estimate $\left(2^{k}\right)^{2}-\left(2^{k}\right)$ transition probabilities. Whereas with the independence assumption, there are only $2 k$ estimated parameters. In our model with three state variables, the reduction due to the independence assumption is from 56 to 6 estimated parameters, making estimation feasible.

Maximum-likelihood estimates of the parameters are obtained by maximizing the log of the expected likelihood or

$$
\sum_{t=1}^{T} \ln \left(\sum_{i=0}^{1} \sum_{j=0}^{1} \sum_{k=0}^{1} \operatorname{Prob}\left(S 1_{t}=i, S 2_{t}=j, S 3_{t}=k \mid Y_{t-1}\right) L_{t}^{(i, j, k)}\right)
$$


where the student- $t$ densities are

$$
\begin{aligned}
\ln L_{t}^{(i, j, k)}= & \ln \Gamma(.5(n+1))-\ln \Gamma(.5 n)-.5 \ln \left(\pi n \sigma^{2}\left(S 3_{t}=k\right)\right) \\
& -.5(n+1) \ln \left(1+\frac{\varepsilon\left(S 1_{t}=i, S 2_{t}=j\right)_{t}^{2}}{n \sigma^{2}\left(S 3_{t}=k\right)}\right)
\end{aligned}
$$

and $\Gamma$ is the gamma function.

\section{Estimation Results and Interpretation}

The monthly model is based on estimates for the 1974:1-1987:12 period. For the monetary base $(M B)$ a monthly average series is used, which takes account of the reserve requirements effects. ${ }^{6}$ The consumer price index is used as the price variable $(P)$, and the Swiss franc/Deutsche mark exchange rate is used for $(e)$. Both the series for $M B$ and $P$ are seasonally adjusted. The data source is the SNB's databank.

Three versions of the general model described by equations (1) to (6) are estimated and summarized in Table 1. In Model 1 there is no feedback from the price level. Here the estimated long-run inflation target $\left(\lambda_{0}\right)$ fluctuates within a relatively narrow band, essentially between one and three percent. Without price-level feedback, the inflation rate is targeted period-by-period. In the exchange-rate targeting, the degree of rebasing is

\footnotetext{
${ }^{6}$ Under the pre-1988 system of contemporaneous reserve accounting, the SNB enforced the reserve requirements at the end of each month. This created a sharp rise in reserve demand and was accommodated by the SNB to some extent. These end-of-month effects, also known as the ultimo effect, are averaged out in our series. In the out-of-sample period from 1988-1994, lagged reserve accounting prevailed. The reserve requirements are based on an average of the previous month. This resulted in the disappearance of the ultimo effect. Therefore, a monthly seasonally adjusted figure for the monetary base was used for the post-1988 period.
} 
less than one in both states $\left(\delta_{2}(S 2=0)=.832\right.$ and $\left.\delta_{2}(S 2=1)=.137\right)$, implying, respetively, gradual and relatively rapid accommodation of drift in the exchange rate target. Significant conditional heteroskedasticity appears in the form of markov switching in the scale, $\sigma^{2}(S 3)$, of the variance. As in all heteroskedastic models, observations from the high-variance state receive less weight. This implies that we are more cautious about inferring shifts in the long-run inflation target, for example, when in the high-variance state.

Model 2 permits feedback from the price level, as opposed to period-by-period inflation targeting, to affect base growth. Overall, the parameter estimates of Model 2 are similar to those of Model 1. The feedback component for the price level is found to be insignificant in both states. Tests of Model 1 against Model 2 are complicated by the fact that $\delta_{1}$ is not identified in Model 1. Thus, the likelihood-ratio test statistic does not have its standard chi-square distribution. Nevertheless, the small difference of 0.97 between the log-likelihood values of Models 1 and 2 and the insignificant feedback coefficients for prices $\left(\lambda_{1}\right)$ suggests that Model 1's specification should not be rejected in favor of Model 2.

Model 3 restricts Model 1 to have a constant long-run inflation target, $\lambda_{0}$. In this case two transition probabilities from Model $1, p_{1}$ and $q_{1}$, are not ideutified under the null of $\lambda_{0}(S 1=0)=\lambda_{0}(S 1=1)$. Thus, the likelihood-ratio test statistic again has a nonstandard distribution, but the change in the log-likelihood from restricting $\lambda_{0}$ is greater than 25 , which suggests that the restriction can be rejected.

Several graphs based on Model 1 are presented in order to illustrate the findings. In all of the graphs, we have in-sample results through December 1987 and out-of-sample 
results thereafter. Figure 2 plots a one-year moving average of actual Swiss inflation and the model-implied inflation target, which varies between one and three percent. The low level and narrow range of the model-implied inflation target lends credence to the SNB's claims that monetary targeting has been geared towards price stability.

Actual and model-implied quarterly growth of the Swiss monetary base are plotted in figure 3. The model does not fit well the first few observations following the collapse of the Bretton Woods system, before monetary targeting took hold. Between the mid-1970s and 1987 , however, the model-implied growth rates generally match the level and volatility of base growth. In the post-1988 out-of-sample period, in particular, the model fulfills its indicator function by pointing out that actual base growth between late 1989 and mid1992 was too strong to be consistent with inflation below three percent. Inflation began to accelerate in late 1989 , even though the official base target growth rate of one percent was being slightly undershot due to a large shock to reserve demand which stemmed from two sources: a change in reserve requirements and the introduction of the SIC system. During this transition period, reserves fell from ten to three billion Swiss francs. Although base growth contracted, it did not fall quickly enough to accommodate the decrease in the demand for base money. During this period, our indicator model suggests that base growth should have been about two percentage per quarter lower to maintain inflation in the one to three percent range (see figure 3). By mid-1992, the indicator model shows that base growth was back on track to steer the inflation rate below three percent. Based on the 1988-94 out-of-sample performance, we claim that the indicator model did not lose 
relevance in the face of the sort of regulatory changes and technological financial innovations that McCallum (1988) contended a good nominal targeting procedure ought to sustain.

With respect to exchange-rate feedback, Figure 4 plots the model-implied exchange rate target and the actual exchange rate. The graph shows that at times, notably in 1978 and to a lesser extent in early 1982 , the vertical distance between the two exchange rates is relatively large. During these episodes the SNB raised base growth in an attempt to arrest the appreciation of the Swiss franc.

Figure 5 takes the "exchange-rate gaps" from Figure 4 and multiplies them by the feedback parameter, $\lambda_{2}$, to estimate the influence exchange-rate feedback had on quarterly money growth. This graph shows estimates of the portion of the 1978-79 surge in base money growth that would be a response to the strong appreciation of the Swiss franc in 1978. The actual surge in base growth, however, was substantially larger than the modelimplied surge. Thus, base growth in 1978-79 might have been higher than necessary to achieve the goal of stabilizing the value of the Swiss franc.

\section{Conclusions}

This paper develops an implicit inflation-targeting rule with exchange-rate feedback and markov-switching parameters as an estimable model of Swiss monetary policy choices regarding base money growth. The long-run inflation target is estimated to switch roughly between one and three percent in the 1974-1987 period. The identification of such a narrow band implies that, even when intervening on behalf of the exchange rate, the SNB was not 
prepared to allow money growth to deviate for prolonged periods from the path implied by either of two relatively low-inflation regimes. The post- 1987 out-of-sample performance reveals that the specification is robust to shocks stemming from changes in reserve requirements and technological innovations in the payments system, as such shocks greatly affected the size and composition of the base starting in 1988. More importantly, our results show that Swiss monetary policy would have been tighter during the most recent inflation cycle if the implicit model had been used as a reference guide for SNB policymaking. The gap between the actual and the model implied monetary base growth was closed gradually by mid-1993 only after higher than normal inflation had been observed for more than three years. 


\section{Appendix: Forecasts of Real Base Growth}

The forecasts of real base growth for the in- and out-of-sample periods are based on a model by Kim (1993). Let $(M B / P)$ stand for the real monetary base, $3 M O$ the 3 -month Euro franc rate and $P$ the consumer price index. ${ }^{7}$ The model generating the forecast is

$$
\begin{aligned}
\begin{aligned}
\Delta l n\left(\frac{M B}{P}\right)_{t}= & \beta_{0 t}+\beta_{1 t} \Delta 3 M O_{t-1}+\beta_{2 t} \Delta l n P_{t-1}+\beta_{3 t} \Delta \ln \left(\frac{M B}{P}\right)_{t-1}+e_{t}, \\
& e_{t} \sim \operatorname{Normal}\left(0, h_{t}\right), \\
h_{t}= & \sigma_{0}^{2}+\left(\sigma_{1}^{2}-\sigma_{0}^{2}\right) S_{t}, S_{t} \in\{0,1\}, \sigma_{1}^{2}>\sigma_{0}^{2}, \\
\operatorname{Probability}\left(S_{t}=0 \mid S_{t-1}=0\right)= & p_{1}, \\
\operatorname{Probability}\left(S_{t}=1 \mid S_{t-1}=1\right)= & p_{2} .
\end{aligned}
\end{aligned}
$$

The variances of the error terms are assumed to switch between a low and a high state according to a first-order markov process. Persistence of low and high volatility states is increasing in $p_{1}$ and $p_{2}$, respectively. The time-varying coefficients follow a random walk process

$$
\beta_{t}=\beta_{t-1}+v_{t}, v_{t} \sim \operatorname{Normal}(0, Q) .
$$

The random walk assumption implies that agents need information before changing their views about the relationships among variables.

\footnotetext{
${ }^{7}$ Monthly measures of unemployment and real retail sales were found to be insignificant as explanatory variables.
} 


\section{References}

Bernanke, B. and F. Mishkin, 1992, Central Bank Behavior and the Strategy of Monetary Policy, in O. Blanchard and S. Fischer, eds., NBER Macroeconomics Annual, (MIT Press, Cambridge) 183-228.

Hall, T. E., 1990, McCallum's base growth rule: Results for the United States, West Germany, Japan and Canada, Weltwirtschaftliches Archiv 126, 630-642.

Hamilton, J., 1989, A new approach to the economic analysis of nonstationary time series and the business cycle, Econometrica 57, 357-384.

Kim, C. J., 1993, Sources of money growth uncertainty and economic activity: The timevarying parameter with heteroskedastic disturbances, Review of Economics and Statistics, 483-492.

Kim, C.J., 1994, Dynamic linear models with markov switching, Journal of Econometrics $56,1-22$.

Lusser, M., 1990, Monetary policy and banking stability in: Zuhayr Mikdashi, ed., Bankers' and Public Authorities' Management of Risks, (Macmillan, London).

McCallum, B. T., 1987, The case for rules in the conduct of monetary policy: A concrete example, Economic Review, Federal Reserve Bank of Richmond, September/October, 1018.

McCallum, B. T., 1988, Robustness properties of a rule for monetary policy, CarnegieRochester Conference Series on Public Policy 29, 173-204.

McCallum, B. T., 1993, Specification and analysis of a monetary policy rule for Japan, Bank of Japan Monetary and Economic Studies 11, 1-45.

McCallum, B. T., 1994, Monetary policy rules and financial stability, NBER Working Paper No. 4692.

Rich, G., 1995, Monetary targets as a policy rule: Lessons from Swiss experience, paper presented at the Swiss National Bank conference on Rules versus Discretion in Monetary Policy, March 15-19, Gerzensee, Switzerland.

Vital, C. and D. L. Mengle, 1988, SIC: Switzerland's new electronic interbank payment system, Federal Reserve Bank of Richmond, Economic Review, November/December, 1227. 


\begin{tabular}{|c|c|c|c|}
\hline \multicolumn{4}{|c|}{ Table 1: Models of Inflation Targeting (eqns. 1-6): 1974:1-1987:12 } \\
\hline parameter & $\begin{array}{c}\text { Model } 1 \\
\text { no price feedback }\end{array}$ & $\begin{array}{c}\text { Model 2 } \\
\text { price feedback }\end{array}$ & $\begin{array}{l}\text { Model 3 } \\
\text { constant inflation target }\end{array}$ \\
\hline $\begin{array}{c}\lambda_{0}(S 1=0) \\
\text { inflation target: low state }\end{array}$ & $\begin{array}{c}.844 \\
(.143)\end{array}$ & $\begin{array}{l}.848 \\
(.137)\end{array}$ & $\begin{array}{l}3.06 \\
(.127)\end{array}$ \\
\hline $\begin{array}{c}\quad \lambda_{0}(S 1=1) \\
\text { inflation target: high state }\end{array}$ & $\begin{array}{c}3.22 \\
(.114)\end{array}$ & $\begin{array}{c}3.25 \\
(.119) \\
\end{array}$ & \begin{tabular}{|l|}
3.06 \\
$(.127)$ \\
\end{tabular} \\
\hline $\begin{array}{c}\lambda_{1}(S 1=0) \\
\text { price level feedback }\end{array}$ & set to zero & $\begin{array}{l}.758 \\
(.586)\end{array}$ & set to zero \\
\hline $\begin{array}{c}\lambda_{1}(S 1=1) \\
\text { price level feedback }\end{array}$ & set to zero & $\sim 0$ & set to zero \\
\hline $\begin{array}{c}\delta_{1}(S 1=0) \\
\text { price target drift }\end{array}$ & set to zero & $\sim 0$ & set to zero \\
\hline $\begin{array}{c}\delta_{1}(S 1=1) \\
\text { price target drift }\end{array}$ & set to zero & $\begin{array}{c}.772 \\
(.302)\end{array}$ & set to zero \\
\hline $\begin{array}{c}\lambda_{2}(S 2=0) \\
\text { exchange rate feedback }\end{array}$ & $\begin{array}{l}.150 \\
(.058)\end{array}$ & $\begin{array}{l}.132 \\
(.058)\end{array}$ & $\begin{array}{l}.067 \\
(.084) \\
\end{array}$ \\
\hline $\begin{array}{c}\lambda_{2}(S 2=1) \\
\text { exchange rate feedback }\end{array}$ & $\begin{array}{l}1.63 \\
(.227)\end{array}$ & $\begin{array}{l}1.64 \\
(.226)\end{array}$ & \begin{tabular}{|l|}
1.24 \\
$(.288)$
\end{tabular} \\
\hline $\begin{array}{c}\delta_{2}(S 2=0) \\
\text { exch. rate target drift }\end{array}$ & $\begin{array}{c}.832 \\
(.105)\end{array}$ & $\begin{array}{c}.861 \\
(.087)\end{array}$ & $\begin{array}{l}.568 \\
(.021)\end{array}$ \\
\hline $\begin{array}{c}\delta_{2}(S 2=1) \\
\text { exch. rate target drift }\end{array}$ & $\begin{array}{l}.137 \\
(.128)\end{array}$ & $\begin{array}{l}.135 \\
(.128)\end{array}$ & $\begin{array}{l}.825 \\
(.078)\end{array}$ \\
\hline $\begin{array}{c}\sigma^{2}(S 3=0) \\
\text { low variance }\end{array}$ & $\begin{array}{l}.436 \\
(.082)\end{array}$ & $\begin{array}{l}.437 \\
(.079)\end{array}$ & $\begin{array}{l}.377 \\
(.114)\end{array}$ \\
\hline $\begin{array}{c}\sigma^{2}(S 3=1) \\
\text { high variance }\end{array}$ & $\begin{array}{c}17.1 \\
(2.71)\end{array}$ & $\begin{array}{l}16.7 \\
(2.67)\end{array}$ & $\begin{array}{l}11.5 \\
(1.63)\end{array}$ \\
\hline$p_{1}$ & $\begin{array}{l}.903 \\
(.058)\end{array}$ & $\begin{array}{l}.916 \\
(.050)\end{array}$ & not estimated \\
\hline$q_{1}$ & $\begin{array}{l}.971 \\
(.018)\end{array}$ & $\begin{array}{l}.972 \\
(.017)\end{array}$ & not estimated \\
\hline$p_{2}$ & .999 & .999 & \begin{tabular}{|l|}
.988 \\
$(.013)$
\end{tabular} \\
\hline$q_{2}$ & $\begin{array}{c}.989 \\
(.011)\end{array}$ & $\begin{array}{l}.989 \\
(.010)\end{array}$ & $\begin{array}{l}.928 \\
(.047)\end{array}$ \\
\hline$p_{3}$ & $\begin{array}{l}.972 \\
(.021)\end{array}$ & $\begin{array}{c}.974 \\
(.020)\end{array}$ & $\begin{array}{l}.909 \\
(.065)\end{array}$ \\
\hline$q_{3}$ & $\begin{array}{l}.976 \\
(.017)\end{array}$ & $\begin{array}{l}.978 \\
(.017)\end{array}$ & $\begin{array}{l}.980 \\
(.020)\end{array}$ \\
\hline Log-Likelihood & -380.96 & -379.99 & -405.42 \\
\hline No. of parameters & 14 & 18 & 11 \\
\hline
\end{tabular}


Figure 1

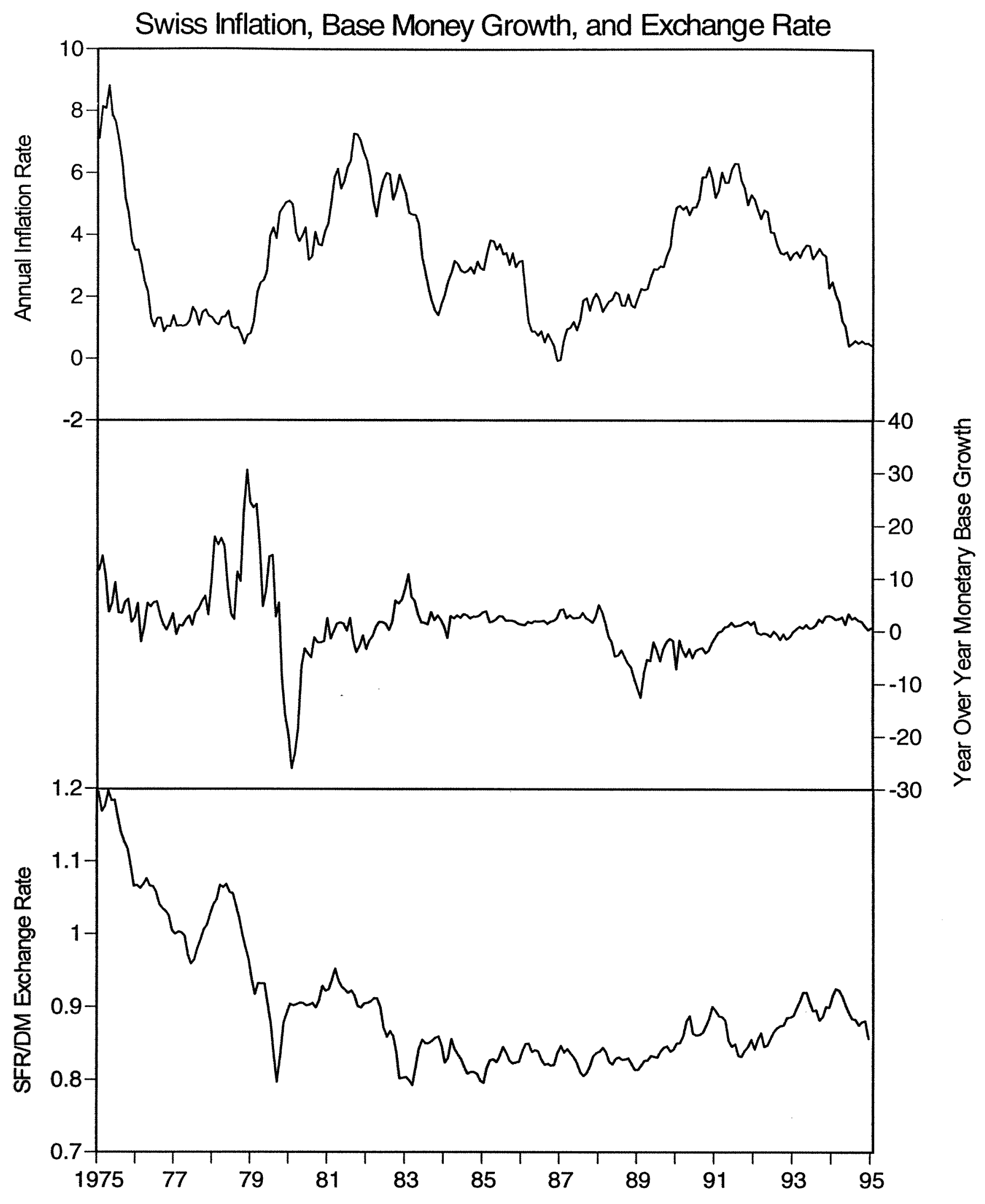




\section{Figure 2}

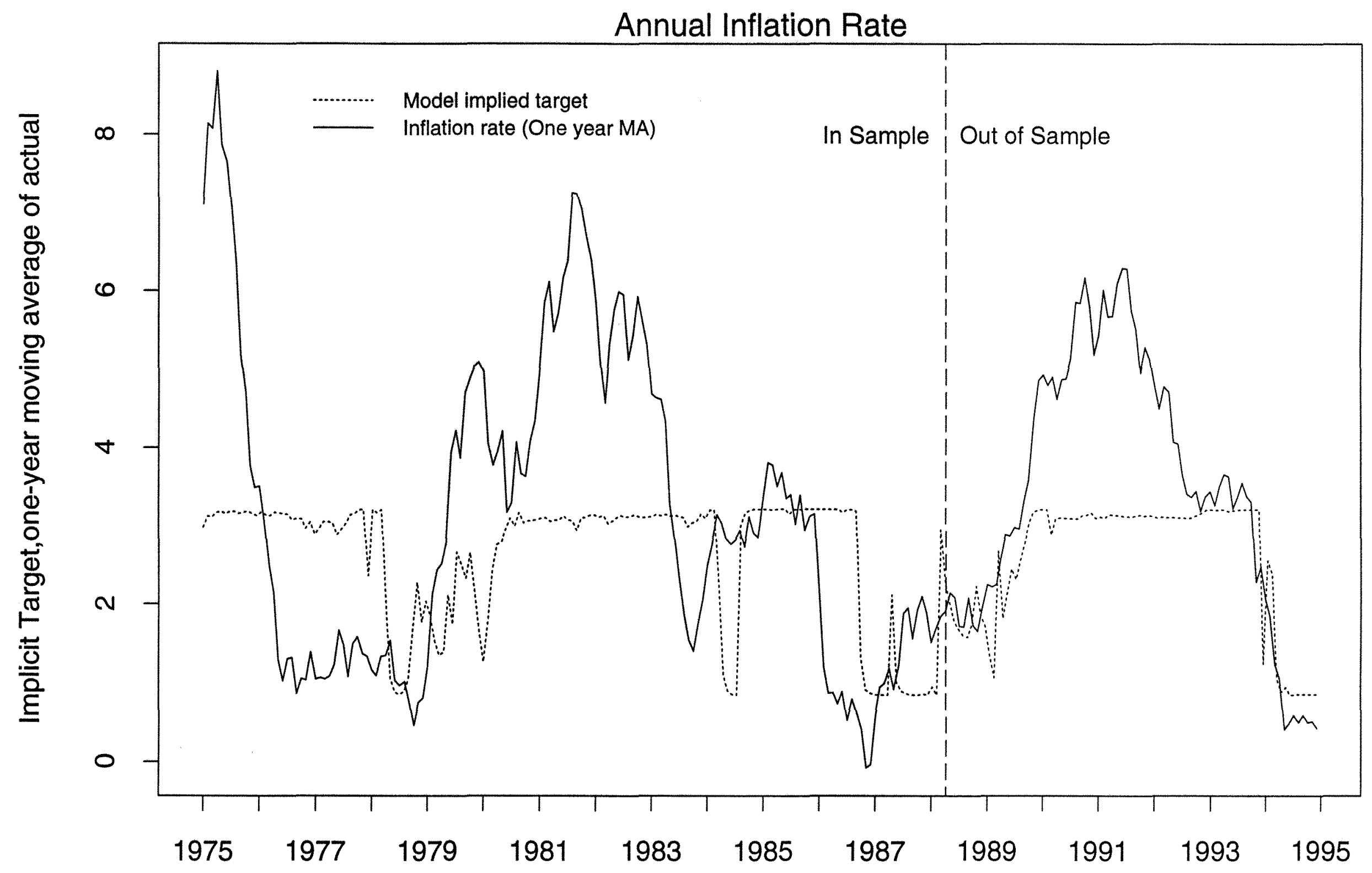




\section{Figure 3}

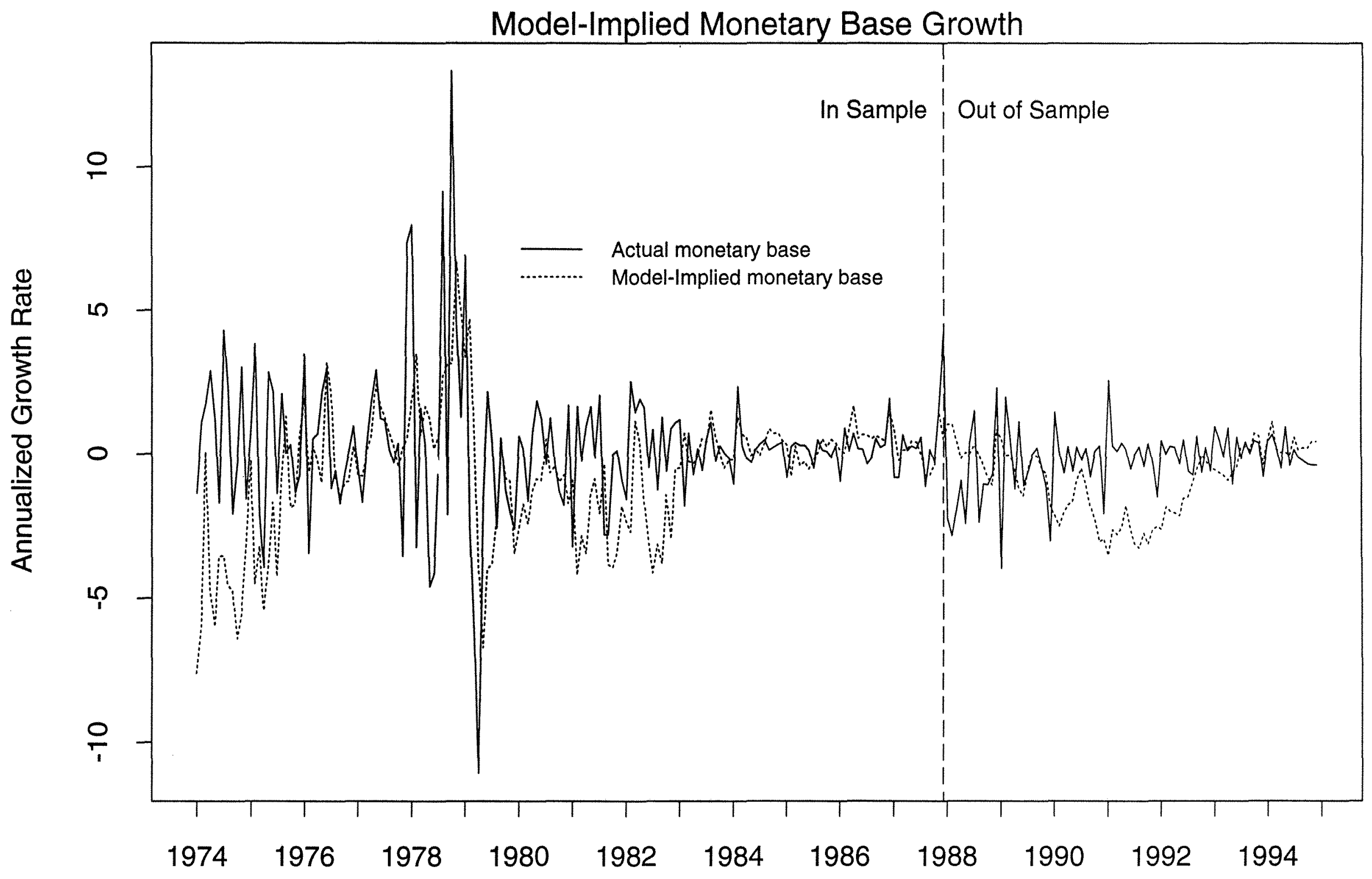




\section{Figure 4}

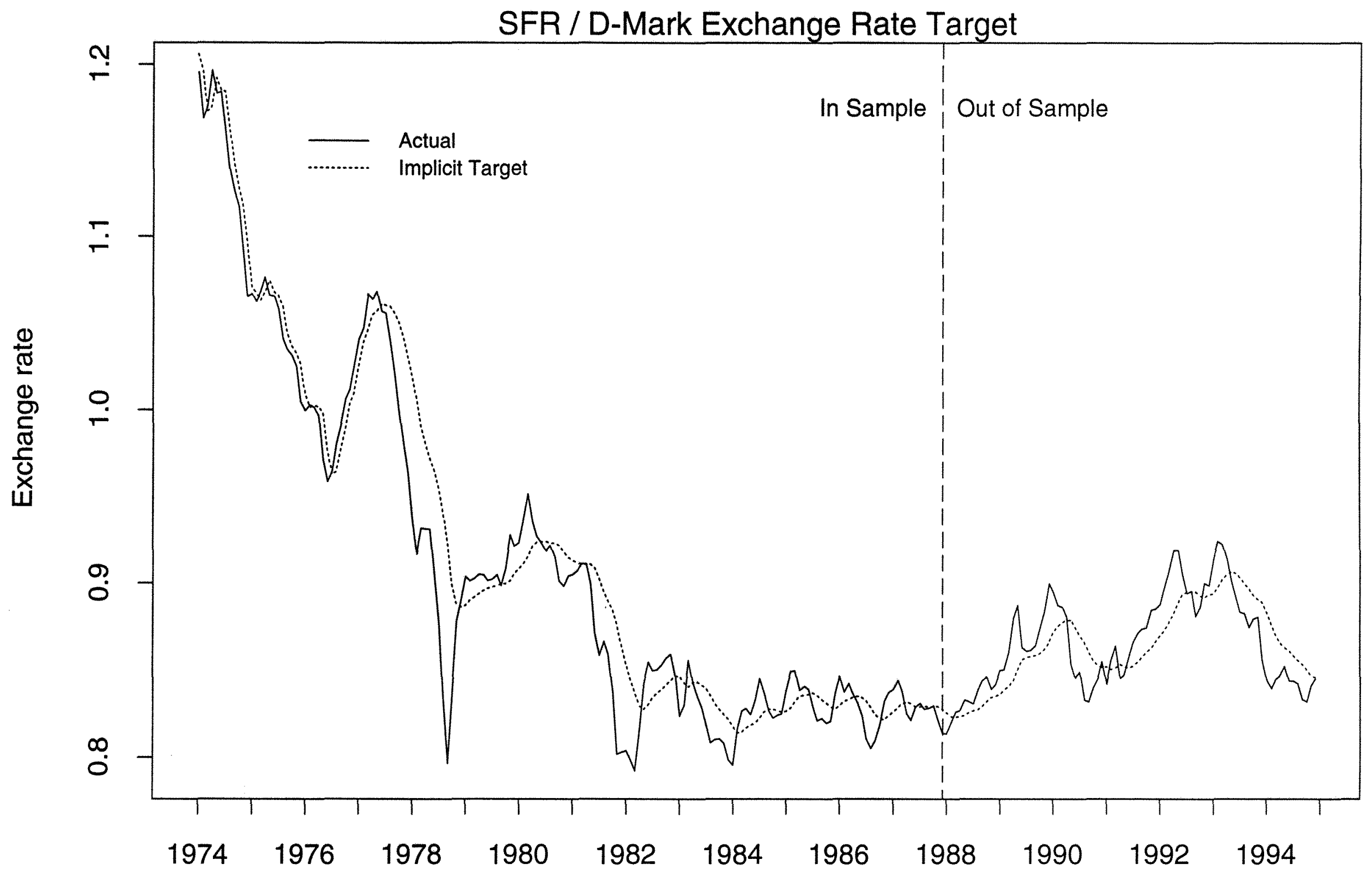




\section{Figure 5}

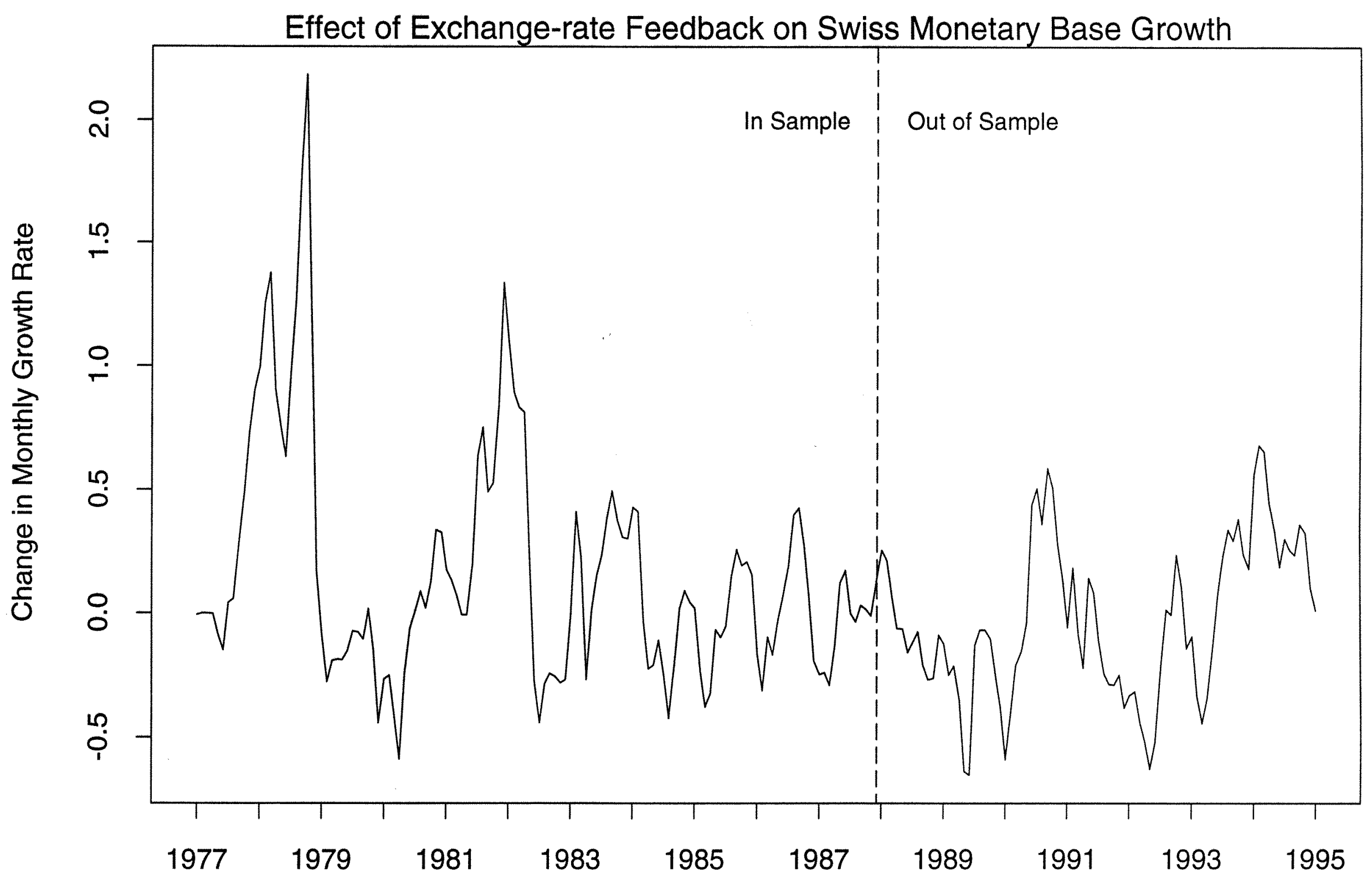

